\title{
Preferences and interests of diabetes social media users regarding a health-promotion intervention
}

This article was published in the following Dove Press journal:

Patient Preference and Adherence

\author{
Elia Gabarron' \\ Enrique Dorronzoro² \\ Meghan Bradway ${ }^{1,3}$ \\ Octavio Rivera-Romero ${ }^{2}$ \\ Rolf Wynn ${ }^{3,4}$ \\ Eirik Årsand 1,3 \\ 'Norwegian Centre for E-health \\ Research, University Hospital of \\ North Norway, Tromsø, Norway; \\ ${ }^{2}$ Department of Electronic Technology, \\ Universidad de Sevilla, Seville, Spain; \\ ${ }^{3}$ Department of Clinical Medicine, \\ Faculty of Health Sciences, UiT - \\ Arctic University of Norway, Tromsø, \\ Norway; ${ }^{4}$ Division of Mental Health \\ and Addictions, University Hospital of \\ North Norway, Tromsø, Norway
}

Correspondence: Elia Gabarron

Norwegian Centre for E-health Research, University Hospital of North Norway,

23 Sykehusveien, Tromsø 9019, Norway

Tel +47 77754030

Fax +47 77754099

Email elia.gabarron@ehealthresearch.no
Background: Nowadays, rapid and accessible participatory research on diabetes can be carried out using social media platforms. The objective of this study was to identify preferences and interests of diabetic social media users regarding a health-promotion intervention targeting them.

Methods: Social media followers of the Norwegian Diabetes Association were invited to participate in the creation of a health-promotion intervention on diabetes by expressing their opinions through an online questionnaire posted on Facebook, Twitter, and Instagram. The questionnaire asked participants about their demographics and preferences regarding type of health content: format, frequency, and channels to deliver content. Questions regarding the perceived quality of diabetes-related information and satisfaction with content on social media were also included.

Results: The questionnaire was answered by 346 participants: 332 (96\%) of those were reached via Facebook, $66.5 \%$ of respondents $(n=230)$ identified themselves as women, $54 \%(n=187)$ as individuals diagnosed with type 1 diabetes, and $71 \%(n=235)$ were aged $30-64$ years. The preferred type of content was "research and innovation on diabetes", selected by $78.0 \%$ of the respondents. "Text format" was the choice for $93.4 \%$, and $97.3 \%$ would prefer to find healthpromotion content on Facebook. There was heterogeneity in the desired frequency of this content. In a scale ranging from 0 to 100 , the perceived quality of diabetes-related information on social media was $62.0 \pm 1.2$ and satisfaction with such content $61.9 \pm 1.3$.

Conclusion: The approach used in this study was successful in reaching and involving participants quickly, and could also potentially increase diabetes patients' engagement and satisfaction with health-promotion interventions, enhance their sense of community, and thus help people attain healthier lifestyles. It is a limitation that our sample might not have been fully representative, as the most interested social media users might have chosen to participate.

Keywords: community-based participatory research, diabetes, health promotion, health education, social media

\section{Introduction}

Evidence of the benefits of community-based participatory research in health care is growing. ${ }^{1-6}$ "Participatory" refers to the involvement of representatives of those who would be the primary beneficiaries of that research., ${ }^{7,8}$ This kind of research could also offer a series of additional advantages to participants in the public health sector compared to traditional top-down approaches. One of these advantages is the potential to increase the interest of participants (ie, people affected by a health condition) in a project in which they have participated. Participatory health research can enhance participants' psychological sense of community ${ }^{9,10}$ and raise their awareness about their chronic condition, which may enable them to have greater autonomy and better health. ${ }^{7,11}$ In addition, participatory approaches could improve researchers' and public 
health promoters' understanding of what people affected with chronic diseases consider important, and prompt them to tailor intervention programs according to the target audience's preferences and interests. ${ }^{7,8,11-14}$

However, researchers using participatory approaches have repeatedly reported challenges in engaging representatives. ${ }^{15-18}$ Nowadays, the use of online social media could bring new possibilities to attract the attention of these populations and engage them in health-promotion interventions. ${ }^{19-24}$ Meta-analyses and reviews have reported positive effects of social media use for promoting healthy lifestyles and improving self-management among people affected with chronic diseases. ${ }^{20,22,25-32}$ Social media allow researchers to reach target audiences rapidly. Using social media as platforms for community-based participatory research could also increase the interest and engagement of targeted audiences and thus be a valuable method for the design and delivery of health-promotion programs targeting people with chronic diseases. ${ }^{7,8,11,12}$

Social media have been used in health-promotion planning and intervention design. Balatsoukas et $\mathrm{al}^{33}$ conducted a narrative review of theoretical and empirical factors influencing the effectiveness of social network-enabled interventions. The authors included 42 studies, with 20 showing the use of a theory/model in the design of those interventions. Those 20 interventions were based on a mix of theories, including behavioral change theories, social networking theories, and others. Many of the atheoretical interventions were based on the expected emergent properties of social networks. As an example, AURORA ${ }^{34}$ was focused on the expected positive effects on emotional health if positive experiences are shared. The objectives of the use of social networks in those health interventions were social support, sharing personal experiences and emotions, and education. Social network analysis was performed in several interventions to identify usage patterns that may be used to design future interventions. In other interventions, social networks had a motivational role, including peer pressure, peer-to-peer challenges, games, and competitions.

We are carrying out a community-based participatory research project involving researchers, health care professionals, staff from the Norwegian Diabetes Association, and social media users among members of the Norwegian Diabetes Association. Within this project, social media health-promotion content regarding diabetes is to be created according to the preferences of the social media users of the Diabetes Association. This is one of the first studies to combine a participatory approach and social media to involve participants in the creation of a health-promotion intervention for diabetes that will be delivered through online channels. Gabarron et $\mathrm{al}^{35}$ found that most posts published on open social media channels from a diabetes association concerned diabetes awareness, such as recipes, celebrations, or group gatherings. These represented $65 \%$ of the Facebook posts, $88 \%$ of the Instagram posts, and $48 \%$ of the Twitter posts. ${ }^{35}$ Scientific content posts represented $17 \%$ of the messages published on Facebook, $38 \%$ on Twitter, and $8 \%$ on Instagram. ${ }^{35}$

In this study, we are presenting the results to the questionnaires used to identify the interests and preferences of the diabetes association' social media users regarding a health promotion intervention.

\section{Aims}

The objective of this study was to identify preferences and interests of diabetes social media users regarding a healthpromotion intervention targeting them.

\section{Methods}

Members of the Norwegian Diabetes Association ${ }^{36}$ participated, together with researchers and health care professionals, in the design of a project aimed at creating a health-promotion intervention for diabetes, with the goal of promoting a healthy lifestyle using a participatory approach and social media. They actively participated in several stages of the project design, including creation of the questionnaire to collect information required to create content for the intervention. They also participated in distribution of the questionnaire through their social media channels, and are actively involved in the creation of the health-promotion intervention's content, as well as the analysis, interpretation, and dissemination of results of this project. Further details of this research project have been published elsewhere. ${ }^{37}$

The opinion of diabetes social media users is relevant to identify how this health-promotion intervention should be designed, delivered, and maintained. Therefore, all social media followers of the Norwegian Diabetes Association were potentially invited to participate in the definition of content by expressing their opinions through an ad hoc, voluntary, and anonymous online questionnaire. The responses to that questionnaire will be used to design a health-promotion intervention for diabetes to be delivered through social media.

The questionnaire was provided via LimeSurvey, ${ }^{38}$ and hyperlinks to it were posted on the three social media channels of the Diabetes Association (Facebook, Twitter, and Instagram) in November 2017, potentially reaching 
35,000 followers. ${ }^{36} \mathrm{We}$ expected to get the questionnaire answered by about 350 social media users (ie, approximately $1 \%$ of the social media users on the Norwegian Diabetes Association's channels). The questionnaire asked participants to identify themselves by sex, type of respondent (diagnosed with type or type 2 diabetes, family member of a diabetes patient, health care professional, or other), and age group ( $<18,18-29,30-44,45-64$, and $\geq 65$ years). The questionnaire asked them to indicate their preferences regarding a health-promotion intervention on diabetes (respondents were able to choose more than one of the four options, and also to express any preferences that were not specifically mentioned) as per the following categories.

- Preferred type of content: personal aspects of selfmanagement (eg, how to be motivated to follow-up with diabetes), technical aspects of self-management (eg, how to use blood-glucose sensors), research and innovation on diabetes, health care services, and/or interviews or personal stories from other people with diabetes. These types of content categories were chosen following a previous study. ${ }^{35}$

- Content format: text, images, and/or video.

- Content frequency: several times per day, daily, every second or third day, weekly, or more seldom.

- Preferred platform to find this content: Facebook, Twitter, Instagram, and/or others.

Additionally, they were asked to rate on a scale of 0-100 (where 0 meant "very unsatisfied" and 100 "totally satisfied") the quality of diabetes-related information on social media and their satisfaction with the diabetes-related information they found on social media. Descriptive statistics were used to summarize questionnaire answers, and $\chi^{2}$ tests were performed to examine relationships among categorical variables. Data were analyzed using SPSS version 25 for Mac.
This study was assessed by the Norwegian Regional Ethics Committee (REK Sør-Øst) and declared exempt, falling outside the Norwegian Health Research Act $^{39}$ (2017/764C). As the questionnaire was classified as non-medical, voluntary, and anonymous, obtaining further consent was not deemed necessary. The treatment of personal information was approved by a data-protection officer (personvernombudet) at the University Hospital of North Norway (0720).

\section{Results}

In only 1 week, we received 346 responses from social media users: 332 of these questionnaires were from Facebook (96\%), 14 from Instagram (4\%), and 0 from Twitter. A total of 230 identified themselves as women (66.5\%) and $101(29.2 \%)$ as men. Fifteen respondents (4.3\%) did not specify their sex. Table 1 summarizes the reported demographics of the respondents.

A summary of the social media users' preferences for a health-promotion intervention on diabetes (type, format, frequency, and platform) according to type of respondent and by age group can be found in Tables 2 and 3, respectively.

Regarding the preferred type of content, no significant differences were found between sexes. "Research and innovation" was the most commonly cited by all participants, specifically selected by $100 \%$ of those under the age of 18 years $\left(\mathrm{n}=7, \chi_{4,304}^{2}=12.882 ; P=0.12\right)$. Content on "technical aspects of self-management" was more frequently chosen by those aged 18-29 $(n=28,59.6 \%), 30-44(n=62,68.9 \%)$, and 45-64 $(\mathrm{n}=83,63.8 \%)$ years $\left(\chi_{4,304}^{2}=9.856, P=0.043\right)$. "Interviews or personal stories" were more frequently preferred by women $(\mathrm{n}=93,43.9 \%)$ vs men $(\mathrm{n}=24,26.4 \% ; P=0.004)$.

Text format was preferred by almost all adults, and $57.1 \%$ of those aged 18 years and under $\left(\chi_{4,304}^{2}=15.382, P=0.004\right)$. Image format was mostly preferred by social media users

Table I Demographics of social media-user respondents to the questionnaire $(n=346)$

\begin{tabular}{|c|c|c|c|}
\hline & $\begin{array}{l}\text { Men } \\
\text { n (\%) }\end{array}$ & $\begin{array}{l}\text { Women } \\
\text { n (\%) }\end{array}$ & $\begin{array}{l}\text { Total } \\
\text { n (\%) }\end{array}$ \\
\hline \multicolumn{4}{|l|}{ Type of respondent ${ }^{a}$} \\
\hline Diagnosed with type I diabetes & $54(15.6)$ & $133(38.4)$ & $187(54.0)$ \\
\hline Diagnosed with type 2 diabetes & $34(9.8)$ & $39(11.3)$ & $73(2 \mathrm{I} . \mathrm{I})$ \\
\hline Family member of diabetes patient & $13(3.8)$ & $58(16.8)$ & $71(2.5)$ \\
\hline Health care professional & $3(0.9)$ & $19(5.5)$ & $22(6.4)$ \\
\hline \multicolumn{4}{|l|}{ Age group, years } \\
\hline$<18$ & $4(1.2)$ & $6(1.7)$ & $10(2.9)$ \\
\hline $18-29$ & $14(4.0)$ & $38(10.9)$ & $52(15.0)$ \\
\hline $30-44$ & $24(6.9)$ & $72(20.8)$ & $96(27.7)$ \\
\hline $45-64$ & $46(13.3)$ & $93(26.9)$ & $139(40.2)$ \\
\hline$\geq 65$ & $13(3.8)$ & $21(6.1)$ & $34(9.8)$ \\
\hline
\end{tabular}

Note: aMultiple choice available for this category. 
Table 2 Social media users' preferences regarding a health-promotion intervention on diabetes according to type of respondent

\begin{tabular}{|c|c|c|c|c|c|}
\hline & $\begin{array}{l}\text { Diagnosed with } \\
\text { type I diabetes, } \\
\text { n (\%) }\end{array}$ & $\begin{array}{l}\text { Diagnosed with } \\
\text { type } 2 \text { diabetes, } \\
\text { n (\%) }\end{array}$ & $\begin{array}{l}\text { Family member } \\
\text { of diabetes } \\
\text { patient, } \mathbf{n}(\%)\end{array}$ & $\begin{array}{l}\text { Health care } \\
\text { professional, } \\
\text { n (\%) }\end{array}$ & Total, n (\%) \\
\hline $\begin{array}{l}\text { Type of content } \\
\text { Research and innovation on diabetes } \\
\text { Technical aspects of self-management } \\
\text { Personal aspects of self-management } \\
\text { Interviews/personal stories from other } \\
\text { people with diabetes } \\
\text { Content on health care services }\end{array}$ & $\begin{array}{l}135(78.5) \\
123(7 \mid .5) \\
94(54.7) \\
60(34.9) \\
70(40.7)\end{array}$ & $\begin{array}{l}40(61.5) \\
21(32.3) \\
36(55.4) \\
16(24.6) \\
23(35.4)\end{array}$ & $\begin{array}{l}62(9 \mid .2) \\
50(73.5) \\
35(51.5) \\
32(47.1) \\
29(42.6)\end{array}$ & $\begin{array}{l}20(95.2) \\
14(66.7) \\
8(38.1) \\
9(42.9) \\
11(52.4)\end{array}$ & $\begin{array}{l}237(78.0) \\
188(61.6) \\
161(52.8) \\
117(38.5) \\
114(37.5)\end{array}$ \\
\hline $\begin{array}{l}\text { Format of content } \\
\text { Text } \\
\text { Images } \\
\text { Videos }\end{array}$ & $\begin{array}{l}\text { I } 58(92.4) \\
91(53.2) \\
47(27.5)\end{array}$ & $\begin{array}{l}60(95.2) \\
14(22.2) \\
10(15.9)\end{array}$ & $\begin{array}{l}64(94.1) \\
42(61.8) \\
21(30.9)\end{array}$ & $\begin{array}{l}21(100) \\
13(61.9) \\
7(33.3)\end{array}$ & $\begin{array}{l}281(93.4) \\
150(49.8) \\
79(26.2)\end{array}$ \\
\hline $\begin{array}{l}\text { Frequency of content } \\
\text { Daily or several times per day } \\
\text { Every second or third day } \\
\text { More seldom }\end{array}$ & $\begin{array}{l}72(42.9) \\
31(18.5) \\
65(38.7)\end{array}$ & $\begin{array}{l}15(24.2) \\
12(19.4) \\
35(56.5)\end{array}$ & $\begin{array}{l}24(36.4) \\
20(30.3) \\
22(33.3)\end{array}$ & $\begin{array}{l}7(33.3) \\
5(23.8) \\
9(42.9)\end{array}$ & $\begin{array}{l}110(37.3) \\
60(20.3) \\
125(42.4)\end{array}$ \\
\hline $\begin{array}{l}\text { Platform }^{\text {a }} \\
\text { Facebook } \\
\text { Instagram } \\
\text { Twitter }\end{array}$ & $\begin{array}{l}165(97.1) \\
36(21.2) \\
7(4.1)\end{array}$ & $\begin{array}{l}60(96.8) \\
3(4.8) \\
1(1.6)\end{array}$ & $\begin{array}{l}67(98.5) \\
\mathrm{II}(16.2) \\
5(7.4)\end{array}$ & $\begin{array}{l}21(100) \\
7(33.3) \\
I(4.8)\end{array}$ & $\begin{array}{l}291(97.3) \\
52(17.4) \\
14(4.7)\end{array}$ \\
\hline
\end{tabular}

Note: aultiple choice available for each type of preferred content (except frequency) and by type of respondent.

aged 18-29 years $\left(\chi_{4,304}^{2}=43.731, P<0.001\right)$. Video format was the more frequently chosen format by respondents $<18$ years old $\left(\chi_{4,304}^{2}=12.485, P=0.014\right)$. No significant differences between sexes regarding content format were found.

Nearly all the questionnaires were answered following a link from Facebook, and none from Twitter. Of the respondents from Facebook, 272 (90.4\%) indicated being interested in text format, $143(49.3 \%)$ in images, and $73(25.2 \%)$ in video. Of the respondents from Instagram, nine (81.8\%) indicated being interested in text format, seven (63.6\%) in images, and six (54.5\%) in video.

Regarding content frequency, no significant differences were found between sexes or age groups. Regarding which of the platforms on which they would like to find

Table 3 Social media users' preferences regarding a health-promotion intervention on diabetes according to age group

\begin{tabular}{|c|c|c|c|c|c|c|}
\hline & $\begin{array}{l}<18 \text { years, } \\
\text { n (\%) }\end{array}$ & $\begin{array}{l}\text { I 8-29 years, } \\
\text { n (\%) }\end{array}$ & $\begin{array}{l}\text { 30-44 years, } \\
\text { n (\%) }\end{array}$ & $\begin{array}{l}\text { 45-64 years, } \\
\text { n (\%) }\end{array}$ & $\begin{array}{l}\geq 65 \text { years, } \\
\text { n (\%) }\end{array}$ & Total, n (\%) \\
\hline $\begin{array}{l}\text { Type of content } \\
\text { Research and innovation on diabetes } \\
\text { Technical aspects of self-management } \\
\text { Personal aspects of self-management } \\
\text { Interviews/personal stories from other } \\
\text { people with diabetes } \\
\text { Content on health care services }\end{array}$ & $\begin{array}{l}7(100) \\
2(28.6) \\
5(71.4) \\
4(57.1) \\
3(42.9)\end{array}$ & $\begin{array}{l}37(78.7) \\
28(59.6) \\
30(63.8) \\
22(46.8) \\
18(38.3)\end{array}$ & $\begin{array}{l}79(87.8) \\
62(68.9) \\
42(46.7) \\
39(43.3) \\
31(34.4)\end{array}$ & $\begin{array}{l}90(69.2) \\
83(63.8) \\
71(54.6) \\
44(33.8) \\
49(37.7)\end{array}$ & $\begin{array}{l}24(80.0) \\
13(43.3) \\
13(43.3) \\
8(26.7) \\
13(43.3)\end{array}$ & $\begin{array}{l}237(78.0) \\
188(61.8) \\
161(53.0) \\
117(38.5) \\
114(37.5)\end{array}$ \\
\hline $\begin{array}{l}\text { Format of content } \\
\text { Text } \\
\text { Images } \\
\text { Videos }\end{array}$ & $\begin{array}{l}4(57.1) \\
4(57.1) \\
4(57.1)\end{array}$ & $\begin{array}{l}44(95.7) \\
37(80.4) \\
17(37.0)\end{array}$ & $\begin{array}{l}84(94.4) \\
53(59.6) \\
28(31.5)\end{array}$ & $\begin{array}{l}12 \mid(93.8) \\
53(41.1) \\
26(20.2)\end{array}$ & $\begin{array}{l}28(93.3) \\
3(10.0) \\
4(13.3)\end{array}$ & $\begin{array}{l}281(93.4) \\
150(49.8) \\
79(26.2)\end{array}$ \\
\hline $\begin{array}{l}\text { Frequency of content } \\
\text { Daily or several times per day } \\
\text { Every second or third day } \\
\text { More seldom }\end{array}$ & $\begin{array}{l}3(42.9) \\
\text { I }(14.3) \\
3(42.9)\end{array}$ & $\begin{array}{l}13(28.3) \\
13(28.3) \\
20(43.4)\end{array}$ & $\begin{array}{l}34(39.1) \\
16(18.4) \\
37(42.5)\end{array}$ & $\begin{array}{l}50(40.0) \\
25(20.0) \\
50(40.0)\end{array}$ & $\begin{array}{l}10(33.3) \\
5(16.7) \\
15(50.0)\end{array}$ & $\begin{array}{l}110(37.3) \\
60(20.3) \\
125(42.4)\end{array}$ \\
\hline $\begin{array}{l}\text { Platform }^{a} \\
\text { Facebook } \\
\text { Instagram } \\
\text { Twitter }\end{array}$ & $\begin{array}{l}6(87.5) \\
4(57.1) \\
I(14.3)\end{array}$ & $\begin{array}{l}43(95.6) \\
16(35.6) \\
I(2.2)\end{array}$ & $\begin{array}{l}88(98.9) \\
18(20.2) \\
6(6.7)\end{array}$ & $\begin{array}{l}126(98.4) \\
13(10.2) \\
6(4.7)\end{array}$ & $\begin{array}{l}28(93.3) \\
1(3.3) \\
0\end{array}$ & $\begin{array}{l}291(97.3) \\
52(17.4) \\
14(4.7)\end{array}$ \\
\hline
\end{tabular}

Note: alt was possible to choose several options for each type of preferred content (except frequency). 
health-promotion content, no significant differences between sexes were found, except for Twitter: although very uncommonly chosen, it was more frequently preferred by men $(n=8$, $9.0 \%)$ than women $(\mathrm{n}=6,2.9 \% ; P=0.022)$. Instagram was the media more frequently chosen by participants $<18$ years old $\left(\chi_{4,99}^{2}=27.322, P<0.001\right)$.

Regarding the perceived quality of diabetes-related information on social media (on a scale of 0-100), the respondent's average rating was $62.0 \pm 1.2$ (median 60 ). The average satisfaction rate with the diabetes-related content on social media was 61.9 \pm 1.3 (median 60). No differences were found in average ratings on perceived quality of information or satisfaction with content between men and women, the different age groups, or types of respondents.

\section{Discussion}

\section{Summary of main findings}

In only 1 week, the online questionnaire posted on the three social media channels from the Norwegian Diabetes Association was answered by 346 participants, almost all from Facebook. Two-thirds of respondents identified themselves as women, $71 \%$ as aged $30-64$ years, and 54\% as individuals diagnosed with type 1 diabetes.

The participants, social media users from the Norwegian Diabetes Association who accessed the study mainly from Facebook, expressed much interest in finding health-promotion content on Facebook, focusing on diabetes research and innovation, and for content presented in text format. The average perceived quality of diabetes-related information on social media was rated 62.0 , and satisfaction with such content was rated 61.9.

\section{Social media users' interests and perceived quality and satisfaction of diabetes-related information}

Correct and appropriate information is the basis for optimal self-management. Several studies have found that in the last couple of decades, Norwegians in general have become increasingly reliant on the Internet for information about health and illness. ${ }^{35-37}$ Our present study finds that users of diabetes social media groups are interested in receiving diabetes-related information through social media channels, such as Facebook, Instagram, and Twitter. In addition, the youngest might prefer online video-based information, a format offered earlier by YouTube, Vimeo, and other online video-sharing platforms, and now also available on almost every social media channel. Patients are familiar with these online services, increasingly through mobile platforms, and most use one or more of the social media services every day for obtaining information and communicating, both professionally and privately. ${ }^{38-42}$

It is interesting to note that while the main interest in closed diabetes social media groups seems to be related to self-management, ${ }^{33,43}$ the responses from mainly diabetes patients through their patient organization found in this study reflect most interest in diabetes research and innovation. This discrepancy might be related to the fact that users feel freer to discuss personal issues and self-management in a closed group on social media, as reported in a previous study, where it was found that mainly diabetes self-management messages were posted in closed groups. ${ }^{35}$

The questionnaire respondents rated the quality of diabetes-related information on social media an average of 62.0 points and their satisfaction with such content 61.9 (scale 0-100). With the launch of the health-promotion intervention based on social media users' preferences and interest, we expect to improve their satisfaction and views regarding the quality of content.

\section{Participation and engagement with creation of a health-promotion intervention}

This study showed that a group of people affected with diabetes had an interest in participating in the development of a health-promotion intervention that will target them. Those who responded to the questionnaire were able to identify contents, formats, frequencies, and channels that were meaningful for them, but the community-based participatory approach in this project was broader. Our research project was planned and designed from an early stage in close collaboration with staff at the Norwegian Diabetes Association. By involving social media users of the Diabetes Association in the creation of the health-promotion intervention, this project might also have a positive effect on the four elements mentioned in the sense-of-community theory: ${ }^{9}$ by being asked about their preferences and interests, participants' feeling of belonging to the group could be enhanced; by being able to choose content and formats for the health-promotion intervention, participants' feeling of having influence on the group could increase, which additionally could intensify their interest in the group; participants might feel they will be reinforced, because group members' interests and preferences regarding the healthpromotion intervention will be met (in this case, the healthpromotion intervention will provide them with more content on diabetes research and innovation in text format on the association's Facebook channel); and a shared emotional connection, consisting in sharing the history of having 
developed together the health-promotion intervention that will benefit all group members.

However, using social media for health promotion is not exempt from disadvantages. Due to differences in access to technology, cultural differences, and preferences, the use of social media strategies for public health promotion may in some circumstances increase health inequities. ${ }^{44-50}$ Misinformation occurs very frequently in social media and is rapidly spread. Social media postings containing misinformation may have significant negative effects on people's health. ${ }^{51,52}$ Another issue is that social media groups may be used for malicious behavior. Studies have shown greater incidence and severity of bullying online compared to offline networks, and online bullying may contribute to the development of depression and other problems. ${ }^{53,54}$

\section{Limitations and further research}

Although we received a good amount of completed questionnaires, it is not possible to generalize our findings to all social media users from the Norwegian Diabetes Association, since we can assume we mainly got answers from the most engaged users and we do not have access to personal details of the members for privacy reasons. We asked the respondents which social media channels they preferred for receiving information about diabetes and how often they would like such information. One might assume this information would correspond to their actual social media use (ie, platform and frequency of use), but we did not ask specifically about actual use. Further research should explore social media users' interests, engagement, and satisfaction with a healthpromotion intervention in which they have participated. In future research, collecting data for a longer period might result in a higher number of respondents and thereby the possibility of an even more detailed analysis according to further subcategorization of the respondents.

It has been reported in the scientific literature that people affected with type 2 diabetes and belonging to lower socioeconomic groups have more diabetes-related complications and higher diabetes-related mortality compared to those in higher socioeconomic groups. ${ }^{55-57}$ Future research could consider collecting socioeconomic data of participants to analyze the differences among groups. The results of such an analysis would allow adaptation of interventions to participants' preferences, while also taking socioeconomic status and associated health-related consequences into consideration. As part of this project, we will investigate how the use of a community-based participatory research approach listening to the users' preferences can potentially increase diabetes patients' engagement and satisfaction with the health-promotion intervention and help people attain healthier lifestyles. The findings from this project will be communicated to the scientific community who and shared with the social media users of the Diabetes Association.

\section{Conclusion}

Users of diabetes social media groups are interested in participating in the creation of a health-promotion intervention on diabetes. They are especially interested in knowing more about research and innovations in diabetes, receiving contents in text format, and in finding the contents on Facebook. The use of community-based participatory research to acknowledge users' preferences helped to reach and involve the participants rapidly and could potentially increase diabetes patients' engagement and satisfaction with the health-promotion intervention, enhance their sense of community, and thus help them to attain healthier lifestyles.

\section{Acknowledgments}

This study was funded by Helse Nord RHF's research fund (HNF1370-17). We sincerely thank the Norwegian Diabetes Association, Diabetesforbundet, for their engagement with this study. EDZ is supported by the V Plan Propio de Investigación of the Universidad de Sevilla.

\section{Author contributions}

All authors contributed toward data analysis, drafting and critically revising the paper and agree to be accountable for all aspects of the work. EG and ED additionally contributed to the creation of the on-line questionnaire, and data acquisition. All the authors have reviewed and approved the final version.

\section{Disclosure}

The authors report no conflicts of interest in this work.

\section{References}

1. Vaughn LM, Wagner E, Jacquez F. A review of community-based participatory research in child health. MCN Am J Matern Child Nurs. 2013;38(1):48-53.

2. Wolfenden L, Wyse R, Nichols M, Allender S, Millar L, McElduff P. A systematic review and meta-analysis of whole of community interventions to prevent excessive population weight gain. Prev Med. 2014;62:193-200.

3. DeSmet A, Thompson D, Baranowski T, Palmeira A, Verloigne M, De Bourdeaudhuij I. Is Participatory Design Associated with the Effectiveness of Serious Digital Games for Healthy Lifestyle Promotion? A Meta-Analysis. J Med Internet Res. 2016;18(4):e94.

4. Asher L, Patel V, De Silva MJ. Community-based psychosocial interventions for people with schizophrenia in low and middle-income countries: systematic review and meta-analysis. BMC Psychiatry. 2017; 17(1):355. 
5. Howard-Grabman L, Miltenburg AS, Marston C, Portela A. Factors affecting effective community participation in maternal and newborn health programme planning, implementation and quality of care interventions. BMC Pregnancy Childbirth. 2017;17(1):268.

6. Sacristán JA, Aguarón A, Avendaño-Solá C, et al. Patient involvement in clinical research: why, when, and how. Patient Prefer Adherence. 2016; 10:631-640.

7. International Collaboration for Participatory Health Research (ICPHR). Position Paper 1: What is Participatory Health Research? 2013. Available from: http://www.icphr.org/uploads/2/0/3/9/20399575/ichpr_position_ paper_1_defintion_-_version_may_2013.pdf. Accessed July 17, 2017.

8. Society for Participatory Medicine. What is Participatory Medicine? 2017. Available from: https://participatorymedicine.org/what-isparticipatory-medicine/. Accessed July 17, 2017.

9. McMillan DW, Chavis DM. Sense of community: A definition and theory. J Community Psychol. 1986;14(1):6-23.

10. Vambheim SM, Wangberg SC, Johnsen JA, Wynn R. Language use in an internet support group for smoking cessation: development of sense of community. Inform Health Soc Care. 2013;38(1):67-78.

11. World Health Organization. Taking a participatory approach to development and better health. 2015. Available from: http://www.euro.who. int/_data/assets/pdf_file/0007/294064/Taking-participatory-approachdevelopment-health-malmo-skane.pdf. Accessed July 17, 2017.

12. Syed-Abdul S, Gabarron E and Lau A. Participatory Health Through Social Media. Elsevier, Oxford, UK 2016.

13. Middleton R. The meaning of involvement in an exercise and health promotion program for people with diabetes. School of Nursing, Faculty of Science, Medicine and Health. University of Wollongong, Australia, 2016.

14. Woolf SH, Purnell JQ, Simon SM, et al. Translating evidence into population health improvement: strategies and barriers. Annu Rev Public Health. 2015;36:463-482.

15. Solomon MZ, Gusmano MK, Maschke KJ. The Ethical Imperative And Moral Challenges Of Engaging Patients And The Public With Evidence. Health Aff (Millwood). 2016;35(4):583-589.

16. Shen S, Doyle-Thomas KAR, Beesley L, et al. How and why should we engage parents as co-researchers in health research? A scoping review of current practices. Health Expect. 2017;20(4):543-554.

17. George AS, Mehra V, Scott K, Sriram V. Community Participation in Health Systems Research: A Systematic Review Assessing the State of Research, the Nature of Interventions Involved and the Features of Engagement with Communities. PLoS One. 2015;10(10):e0141091.

18. Balducci S, Sacchetti M, Haxhi J, et al. Physical exercise as therapy for type 2 diabetes mellitus. Diabetes Metab Res Rev. 2014;30(Suppl 1):13-23.

19. Abedin T, Al Mamun M, Lasker MAA, et al. Social Media as a Platform for Information About Diabetes Foot Care: A Study of Facebook Groups. Can J Diabetes. 2017;41(1):97-101.

20. Cotter AP, Durant N, Agne AA, Cherrington AL. Internet interventions to support lifestyle modification for diabetes management: a systematic review of the evidence. J Diabetes Complications. 2014;28(2):243-251.

21. George KS, Roberts CB, Beasley S, Fox M, Rashied-Henry K; Brooklyn Partnership to Drive Down Diabetes (BP3D). Our Health Is in Our Hands: A Social Marketing Campaign to Combat Obesity and Diabetes. Am J Health Promot. 2016;30(4):283-286.

22. Hudnut-Beumler J, Po'e E, Barkin S. The Use of Social Media for Health Promotion in Hispanic Populations: A Scoping Systematic Review. JMIR Public Health Surveill. 2016;2(2):e32.

23. Ng SM. Improvingpatientoutcomes with technology and socialmediainpaediatric diabetes. BMJ Qual Improv Rep. 2015;4(1):u209396.w3846.

24. Tate DF, Lyons EJ, Valle CG. High-tech tools for exercise motivation: use and role of technologies such as the internet, mobile applications, social media, and video games. Diabetes Spectr. 2015;28(1):45-54.

25. Moorhead SA, Hazlett DE, Harrison L, Carroll JK, Irwin A, Hoving C. A new dimension of health care: systematic review of the uses, benefits, and limitations of social media for health communication. $J$ Med Internet Res. 2013;15(4):e85.
26. Bowen S, Sustar H, Wolstenholme D, Dearden A. Engaging teenagers productively in service design. Int J Child Comput Interact. 2013; $1(3-4): 71-81$.

27. Williams G, Hamm MP, Shulhan J, Vandermeer B, Hartling L. Social media interventions for diet and exercise behaviours: a systematic review and meta-analysis of randomised controlled trials. BMJ Open. 2014;4(2):e003926.

28. Laranjo L, Arguel A, Neves AL, et al. The influence of social networking sites on health behavior change: a systematic review and meta-analysis. J Am Med Inform Assoc. 2015;22(1):243-256.

29. An R, Ji M, Zhang S. Effectiveness of Social Media-based Interventions on Weight-related Behaviors and Body Weight Status: Review and Meta-analysis. Am J Health Behav. 2017;41(6):670-682.

30. Stellefson M, Chaney B, Barry AE, et al. Web 2.0 chronic disease selfmanagement for older adults: a systematic review. J Med Internet Res. 2013;15(2):e35.

31. Gabarron E, Årsand E, Wynn R. Social Media Use in Interventions for Diabetes: Rapid Evidence-Based Review. J Med Internet Res. 2018; 20(8):e10303.

32. Gabarron E, Wynn R. Use of social media for sexual health promotion: a scoping review. Glob Health Action. 2016;9:32193.

33. Balatsoukas P, Kennedy CM, Buchan I, Powell J, Ainsworth J. The Role of Social Network Technologies in Online Health Promotion: A Narrative Review of Theoretical and Empirical Factors Influencing Intervention Effectiveness. J Med Internet Res. 2015;17(6):e141.

34. Gay G, Pollak J, Adams P, Leonard JP. Pilot study of Aurora, a social, mobile-phone-based emotion sharing and recording system. J Diabetes Sci Technol. 2011;5(2):325-332.

35. Gabarron E, Bradway M and Arsand E. What are diabetes patients discussing on social media? International Journal of Integrated Care. 2016;16:S14.

36. Diabetes for bundet. Norwegian Diabetes Association. 2018. Available from: https://www.diabetes.no/english/. Accessed.

37. LimeSurvey GmbH. LimeSurvey. 2017. Available from: https://www. limesurvey.org/. Accessed July 17, 2017.

38. LimeSurvey GmbH. LimeSurvey. 2017.

39. Lovdata. Law on Medical and Health Sciences Research (Health Research Act) - Lov om medisinsk og helsefaglig forskning (helseforskningsloven). Lov-2008-06-20-44. 2008.

40. Andreassen HK, Wangberg SC, Wynn R, Sørensen T, Hjortdahl P. Health-related use of the Internet in the Norwegian population. Tidsskr Nor Laegeforen. 2006;126(22):2950-2952. Norwegian.

41. Kummervold PE, Wynn R. Health information accessed on the internet: the development in 5 European countries. Int J Telemed Appl. 2012; 2012:297416.

42. Wangberg S, Andreassen H, Kummervold P, Wynn R, Sørensen T. Use of the internet for health purposes: trends in Norway 2000-2010. Scand J Caring Sci. 2009;23(4):691-696.

43. Coughlin SS, Heboyan V, Young L, De Leo G, Wilkins T. Use of a web portal by adult patients with pre-diabetes and type 2 diabetes mellitus seen in a family medicine outpatient clinic. J Hosp Manag Health Policy. 2018;2:21.

44. Coughlin SS, Williams LB, Hatzigeorgiou C. A systematic review of studies of web portals for patients with diabetes mellitus. Mhealth. 2017;3:23

45. Cui M, Wu X, Mao J, Wang X, Nie M. T2DM Self-Management via Smartphone Applications: A Systematic Review and Meta-Analysis. PLoS One. 2016;11(11):e0166718.

46. Hamine S, Gerth-Guyette E, Faulx D, Green BB, Ginsburg AS. Impact of mHealth chronic disease management on treatment adherence and patient outcomes: a systematic review. J Med Internet Res. 2015; 17(2):e52.

47. Heitkemper EM, Mamykina L, Travers J, Smaldone A. Do health information technology self-management interventions improve glycemic control in medically underserved adults with diabetes? A systematic review and meta-analysis. J Am Med Inform Assoc. 2017; 24(5):1024-1035. 
48. Simacek KF, Nelson T, Miller-Baldi M, Bolge SC. Patient engagement in type 2 diabetes mellitus research: what patients want. Patient Prefer Adherence. 2018;12:595-606.

49. Whitehead M. The concepts and principles of equity and health. Int J Health Serv. 1992;22(3):429-445.

50. Lorenc T, Petticrew M, Welch V, Tugwell P. What types of interventions generate inequalities? Evidence from systematic reviews. J Epidemiol Community Health. 2013;67(2):190-193.

51. Oyeyemi SO, Gabarron E, Wynn R. Ebola, Twitter, and misinformation: a dangerous combination? BMJ. 2014;349:g6178.

52. Bode L, Vraga EK. See Something, Say Something: Correction of Global Health Misinformation on Social Media. Health Commun. 2018; 33(9):1131-1140.

53. O'Keeffe GS. Social Media: Challenges and Concerns for Families. Pediatr Clin North Am. 2016;63(5):841-849.
54. Social Media as a New Venue for Aggression and Bullying. Adolesc Med State Art Rev. 2016;27(2):265-275.

55. Espelt A, Borrell C, Roskam AJ, et al. Socioeconomic inequalities in diabetes mellitus across Europe at the beginning of the 21st century. Diabetologia. 2008;51(11):1971-1979.

56. Connolly V, Unwin N, Sherriff P, Bilous R, Kelly W. Diabetes prevalence and socioeconomic status: a population based study showing increased prevalence of type 2 diabetes mellitus in deprived areas. J Epidemiol Community Health. 2000;54(3):173-177.

57. Bachmann MO, Eachus J, Hopper CD, et al. Socio-economic inequalities in diabetes complications, control, attitudes and health service use: a cross-sectional study. Diabet Med. 2003;20(11):921-929.

\section{Publish your work in this journal}

Patient Preference and Adherence is an international, peer-reviewed, open access journal that focuses on the growing importance of patient preference and adherence throughout the therapeutic continuum. Patient satisfaction, acceptability, quality of life, compliance, persistence and their role in developing new therapeutic modalities and compounds to optimize clinical outcomes for existing disease states are major areas of interest for the journal. This journal has been accepted for indexing on PubMed Central. The manuscript management system is completely online and includes a very quick and fair peer-review system, which is all easy to use. Visit http://www dovepress.com/testimonials.php to read real quotes from published authors. 